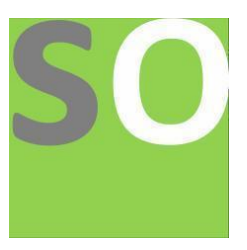

Article title: STRA6 (vitamin A receptor), as a Novel binding receptor of COVID-19

Authors: Mahmoud Elkazzaz[1], Amr Kamel Khalil Ahmed[2], Israa Mohamed Shamkh[3], Mohammed.F. Abo El Magd[4]

Affiliations: department of chemistry and biochemistry , faculty of science , Damietta university ,Egypt[1], public health department, Tuberculosis program, Director of shubra tuberculosis mobile team, First health cluster, ministry of health , Saudia Arabia[2], chemo and bioinformatics lab, Bio search institution, BSRI , Giza, Egypt, Federal university of Alfenas Brazil[3], zoology and Nematode department, Faculty of Agriculture , Al Azhar university , cario , Egypt[4]

Orcid ids: $0000-0003-3477-236 \times[2]$

Contact e-mail: drmedahmed@gmail.com

License information: This work has been published open access under Creative Commons Attribution License http://creativecommons.org/licenses/by/4.0/, which permits unrestricted use, distribution, and reproduction in any medium, provided the original work is properly cited. Conditions, terms of use and publishing policy can be found at https://www.scienceopen.com/.

Preprint statement: This article is a preprint and has not been peer-reviewed, under consideration and submitted to ScienceOpen Preprints for open peer review.

DOI: 10.14293/S2199-1006.1.SOR-.PP8LWHL.v1

Preprint first posted online: 10 September 2021

Keywords: sars cov2, spike proteins, retinoic acid receptors, SARS6, molecular docking, COVID, COVID-19 


\section{STRA6 (vitamin A receptor), as a Novel binding receptor of COVID-19}

Mahmoud Elkazzaz ${ }^{1,4}$, and Tamer Haydara ${ }^{2}$ Israa Mohamed Shamkh ${ }^{3}$ Amr Ahmed ${ }^{3,4}$

1. Department of chemistry and biochemistry, Faculty of Science, Damietta University, Egypt.

2. Department of Internal Medicine, Faculty of Medicine, Kafrelsheikh University, Egypt

3. Chemo and Bioinformatics Lab, Bio Search Research Institution, BSRI. Giza , Egypt, Federal University of Alfenas, Brazil.

4. Director of tuberculosis program Ghubera, public health department, First health cluster ,Ministry of health ,Saudia Arabia.

5. Correspondence, Mahmoud Ramadan Elkazzaz, Amr Ahmed dUniversity, Egypt, Email: mahmoudramadan2051@yahoo.com, ${ }^{2}$ Director of tuberculosis program Ghubera, public health department ,First health cluster , Ministry of health ,Saudia Arabia. Email: drmedahmed@gmail.com

\section{Abstract}

\section{Background}

A global pandemic of pneumonia caused by the severe acute respiratory syndrome coronavirus 2 (SARS-CoV-2) began in Wuhan, China, at the end of 2019. Although, the ACE2 receptor has been shown to be the main entry receptor of COVID-19, but here, in our docking analysis , we predicted and discovered a novel receptor called STRA6 that may play a critical role in the pathogenicity of COVID-19 and explain the common pre and post COVID-19 symptoms with uncertain etiology. STRA6 receptor expressed in many organs and immune cells, upregulated by retinoic acid jm6 (STRA6) was the first protein to be identified in a novel category of proteins, cytokine signaling transporters, due to its ability to function as both a cell surface receptor and a membrane protein that binds to retinol binding protein facilitating cellular uptake of retinol. In agreement to our findings, the main ligand of STRA6 (vitamin/retinol) was found to be significantly reduced during COVID19 infection.

\section{Methods}


The STRA6 receptor protein were submitted to the server for functional interaction associated network between partners for the STRING (Research Online of Interacting Genes/Proteins Data Basis version 10.0)13 .Docking study of each Spike -ACE 2 and STRA6 receptor protein were carried out using HDOCK server (http://hdock.phys.hust.edu.cn/). The binding mode of Spike -ACE 2 and STRA6 receptor protein is retrieved form the PDB https://www.rcsb.org/ with accession number (7DMU , 5sy1)

\section{Results}

Surprisingly, our molecular docking based analysis showed that spike protein Receptor Binding Domain(RDB) of COVID-19 strongly and efficiently binds to STRA6 receptor, definitely to the RDB vital residues of RBP-binding motif located in STRA6 receptor. STRA6 receptor is a membrane receptor responsible for signaling and transporting of Vitamin A(Retinol) from plasma retinol binding protein (RBP) to our cells. In an outstanding manner, COVID-19 Spike protein exhibited high docking score with human STRA6 with low binding energy. The docking score of COVID-19 spike protein was stronger than the docking score of spike protein with ACE2.The surface view of complex reveals that the binding pocket of STRA6- Spike protein and Spike ACE 2 complexes with RMSD (189.44 $\AA$, $1.00 \AA$ ) representatively and docking score $(-341.21,-354.68) \mathrm{kcal} / \mathrm{mol}$ the quality of the receptor and the ligand are LGscore and MaxSub ( $2.416,0.147)$. The spike to bind to RDB of the STRA 6 protein in the ILE 131C , MET 145C , HIS 86A with interface residue( 4.961, 4.953 and 3.271) representatively

\section{In conclusion}

STRA6 mutations results in a broad spectrum of complication related to malformations including congenital heart defects, anophthalmia, alveolar capillary dysplasia, diaphragmatic hernia, lung hypoplasia and mental retardation. Moreover, Retinoic acid metabolism is defective in COVID-19 (cytokine storm), sepsis, ARDS and SIRS. Therefore, We believe that this novel discovery that STRA6 receptor acts as a novel binding receptor for COVID-19 will shed new light on effective drug against COVID-19and explain many previously unexplained pre and post-covid-91 infection symptoms. Therefore, reconstitution of the signaling of retinoid may prove to be a valid strategy for COVID-19 
management. We suggest that Vitamin A supplements and retinoic acid will be promising and effective treatments for COVID-91 infection and its unknown etiology symptoms. . it worth mentioning that aerosolized all- trans retinoic acid is currently under clinical investigation (ClinicalTrials.gov Identifier: NCT05002530)

\section{Introduction}

Normal cellular function depends on vitamin A homeostasis. Plasma retinol-binding protein (RBP) is the only specialized transporter of retinol, the most common form of vitamin $\mathrm{A}$, in the plasma. By recognizing RBP-retinol and triggering retinol release and internalization, the integral membrane receptor STRA6 initiates and controls cellular uptake of vitamin A( (1). STRA6 is a particularly important receptor. because it was found to be the first protein to be recognized as a cytokine signaling transporter, owing to its ability to work as both a membrane protein and a cell surface receptor that facilitates cellular uptake of retinol by attaching to retinol binding protein (2,3). Because of the critical function of vitamin A in the the immune cell development, STRA6 was found to be expressed on all subsets of peripheral blood mononuclear cells at varying amounts. A recent study showed that all $\mathrm{T}$ cell, monocyte, natural killer cell and dendritic cell subsets expressed the retinol binding receptor (STRA6)(3). STRA6 initiates cellular retinol uptake, in immune cells for improving the immune system homeostasis in various populations(3).Many independent studies confirmed that vitamin A uptake mediated by STRA6 from holo-retinol/retinol binding protein complex (holo-RBP) is joined to intracellular proteins $(4,5)$ and the mechanism by which it joins to specific intracellular proteins has been explained (6).It was recently showed that single nucleotide polymorphisms or mutations (SNPs) in STRA6 are connected with the recurrence of type 2 diabetes in humans (7). Moreover, Pasutto et al. (7)reported that STRA6 mutations associated with lung malformations and many heart, eye diaphragm as well as retardation in mentality as in syndrome of Matthew-Wood in humans, validating its reported functions in vitamin A uptake by cells as vitamin A/retinoic 
acid is very critical in the process of organogenesis. STRA6 mutations results in a broad spectrum of complication related to malformations counting congenital heart defects, lung hypoplasia, anophthalmia, alveolar capillary dysplasia, diaphragmatic hernia, and mental retardation(8).

Recent findings showed that mutations in the gene of STRA6 are connected to the congenital microphthalmia of eye malformations, coloboma and anophthalmia(7), (9) (10). STRA6 genetic null mutation in mice model leads to significant reduction of retinoid in the neurosensory retina and retinal pigment epithelium, diminished eye morphology and visual responses, despite the fact the last-mentioned complication is not as serious as in individuals with mutant STRA6 (11) .According to a recent publication, STRA6 is not only a receptor of vitamin A transporter, but it can also act as a cytokine receptor. Upon attaching to holo-RBP, STRA6 is directly phosphorylated at its region of tyrosine residue 643, which, in turn, triggers and recruits activation of STAT 5 and the Janus Kinase 2 gene,( JAK2) (12).

STRA6 seems to be very important receptor and transporter of vitamin A which critically participate in synthesis of retinoic acid which is the active and the main vitamin A metabolite . Nutrients that contains Vitamin A is needed by all mammals. It is required for the proper process of vision in its form of retinaldehyde (retinal). (13) ; as retinoic acids (RAs), it provides ligands for RAR (retinoic acid receptor) and RXR (retinoid X receptor) nuclear receptor transcription factors (14). Consequently, retinoid metabolism affects numerous biological processes (15), with many disease implications from viral infection and cancer to blindness $(16,17)$. In the world Vitamin A deficiency is the third most popular nutritional deficiency, affecting of millions of children and pregnant women life (18).

Retinoic acid(RA) is a morphogen and important metabolite synthesized from vitamin A (retinol) (19). Two dehydrogenasecatalyzed enzymatic reactions are essential for the production of RA from retinol . Vitamin A( Retinol) is converted to retinal, which is then converted to RA. The RA interacts with retinoic acid X receptor (RXR) and retinoic acid receptor (RAR) which then regulate the expression of targeted gene (19). Based on the investigations and previous researches it is clear that RA play a major modulatory function in the immune 
system. Actually, retinol is an important hormone and immune system regulator.it participates with Zinc for improving the function of the immune system(20) . Retinoids are a molecules that possess qualitative activity relative to all-trans retinol (vitamin A), that includes all-transretinoic acid (RA) retinyl-esters and all-trans retinal (20) . RA is the biologically active retinoid metabolite that, works through its receptors RA receptors (RAR $\beta$, $\alpha$ and $\gamma$ ), regulates the generation of various genes involved many biological pathways including both innate and adaptive immune responses (21). Retinoids act as enhancers of the Tcell mediated innate immune responses and adaptive immunity via induction of antigen presenting dendritic cells (DCs), NK cells and innate lymphoid cells (ILCs) $(21,22)$.

It has been established that retinoic acid induce gut-homing receptors on B cells , T cells and ILCs. A mounting body of evidence indicates that RA exert far-reaching impact on fate and functional differentiation of these lymphocytes(23).. Retinoids can directly stimulate the Messenger RNA (mRNA) expression of Interferon-stimulated gene (ISG), including IFN regulatory factor 1 (IRF-1) and retinoic acid-inducible gene I(RIG-I) ( 24,25,26) .Furthermore, retinoic acid plays critical physiological roles in synaptic plasticity, learning and memory(27), hormone production(27,28) and adult neurogenesis(27). Retinoic acid insufficiency in the olfactory epithelium, both in mouse and chick models, causes progenitor cell maintenance failure and, consequently, olfactory neurons differentiation is not maintained . An explant system, showed that renewal of olfactory neurons is inhibited if retinoic acid synthesis was failed in the olfactory epithelium(29) . In the immune system, retinoic acid (RA), metabolite of vitamin $\mathrm{A}$ is known for its critical function in increasing gut-homing molecules in $\mathrm{B}$ and $\mathrm{T}$ lymphocyte cells, boosting tolerance and regulatory T cells (Tregs) (30,31). Synthetic and natural retinoids also have potent inhibitory effects on replication of many viruses, such as $\mathrm{MeV}$, cytomegalovirus, influenza, norovirus and hepatitis B virus (HBV) $(32,33)(27-30)$. There is additional evidence that retinoid signaling activation can effectively suppress coronaviruses. (34).

Our docking study reveals that COVID-19 spike protein binds directly to The integral membrane receptor (STRA6). STRA6 mediates cellular uptake of retinol (vitamin A) by recognizing a molecule of RBP-retinol to trigger release and internalization of retinol(1). Therefore COVID-19 may leads to downregulation of STRA6 receptor leading to inhibition 
the regulatory function of retinoic acid and helps in existing of pre and post-covid-91 infection symptoms and complications such as immune suppression (lymhopenia), Nuerogical disorders, ineffective RIG-I pathway, interferon inhibition, Cytokine storm, Diabetes, Hormonal imbalance, thrombosis, and smell loss.

\section{Material and methods}

Protein-Protein Interaction Network (STRA6 receptor and five interacting partners from both shells of interactions)

The STRA6 receptor protein were submitted to the server for functional interaction associated network between partners for the STRING (Research Online of Interacting Genes/Proteins Data Basis version 10.0)13 (Szklarczyk et al. 2007), with interactions examined at medium confidence.

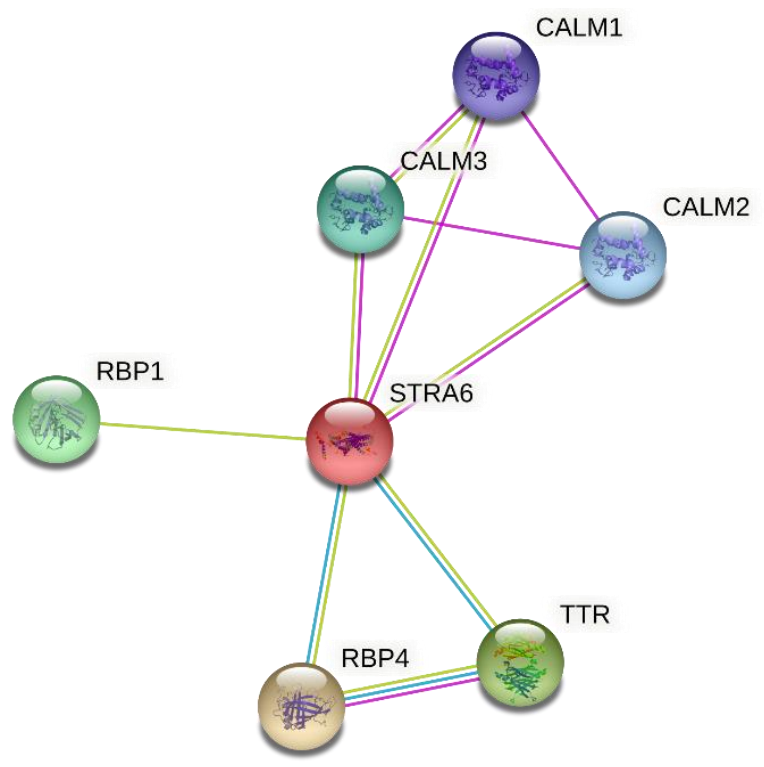

Fig(1). represents the protein-protein interaction network of STRA6 receptor The color nodes describe query proteins and the first shell of interactors, whereas white nodes are 
the second shell of interactors. The large node size represents characterized proteins and smaller nodes for uncharacterized proteins

\section{Molecular docking of proteins(Spike protein with STRA6 and ACE2) HDOCK server}

HDOCK server (http://hdock.phys.hust.edu.cn/) is a highly integrated suite of homology search, template-based modeling, structure prediction, macromolecular docking, biological information incorporation and job management for robust and fast protein-protein docking the server automatically predicts their interaction through a hybrid algorithm of template-based and template-free docking. The HDOCK server distinguishes itself from similar docking servers in its ability to support amino acid sequences as input and a hybrid docking strategy in which experimental information about the protein-protein binding site and small-angle X-ray scattering can be incorporated during the docking and post-docking processes also it has detailed important information about the Complex Template Information in protein protein docking like the ID of the protein which is receptor and ligand protein ID of the chain in each protein which its used in docking complex then the alien length and this important information can allowed us to know where exactly the receptor protein are bind to ligand protein then the quarry coverage and sequence identity to know if the protein are realable and good or its un realable. Correspondingly, new challenges have been presented during the development process of molecular docking approaches, as seen by the community-wide experiment, Critical Assessment of Prediction of Interactions (CAPRI: https://www.ebi.ac.uk/pdbe/complexpred/capri/)14,15. First, with the rapid development of structural genomics16, more and more protein-protein complex structures are being experimentally determined. As such, more information about the binding interfaces of involved proteins is becoming available in the PDB1.In addition, information about The docking energy scores, The ligand RMSDs from the input structures or modeled structures by homology modeling and The interface residues within $5.0 \AA$ from their interacting partner or each other, and the corresponding distances about the residue contacts between proteins may also be derived through an 
evolutionary analysis in sequences 17 or deep learning18. However, how to efficiently incorporate such binding interface information into docking

\section{Molecular docking of proteins}

The molecular docking of protein protein docking is a computational approach in which the binding mode of protein with other protein is assessed. The binding mode of Spike -ACE 2 and STRA6 receptor protein which its retrieved form the PDB https://www.rcsb.org/ with accession number (7DMU , 5sy1) representatively . the Spike -ACE 2 and STRA6 receptor protein was investigated to determine the conservative residues of binding of Spike protein with the ACE to be a control results also Spike with STRA6 receptor to know and discover if the spike protein of the virus are bind with STRA6 receptor in a good binding affinity to declare the mechanism of the interaction. protein .Docking study of each Spike -ACE 2 and STRA6 receptor protein were carried out using HDOCK server There are two working modes in the server :one is the default hybrid docking mode, and the other is the template-free docking mode. First, we put the spike protein after we download it from pdb in accession 6MOJ we enter it on SAMSON software to separate the ACE2 and Spike protein to make docking between them to get the result as a control result to test and know how the complex of spike, STRA6 receptor are how much its efficient and submit into the server, one for receptor (STRA6 receptor) and the other for ligand (spike), in which both amino acid sequences and PDB structures are supported. Then, the server do the template-based modeling of the receptor and ligand molecules by searching thePDB for putative homologous templates based on the sequences of proteins. Then it's found the PDB ID of the two protein then the HDOCK server perform global docking to sample putative binding modes through an FFT-based search method and then

evaluate them without intrinsic scoring function for protein-protein 
interactions. Biological information, such as experimental data on the protein-protein binding site or SAXS profile, can be incorporated during the docking and/or post-docking processes. To provide information about The docking energy scores, The ligand RMSDs from the input structures or modeled structures of the interface residues within $5.0 \AA$ from their interacting partner or each other, to get the corresponding distances about the residue contacts between proteins to assist in an evolutionary analysis in sequences 17 or deep learning18. Finally, the top 100 predicted complex structures are provided to users for download, of which the top 10 models can be visualized through an interactive NGL viewer36 on the result web page. The RDB in extracellular and the membrane part of the star6 receptor with the extracellular, membrane and the third part in the cytosol where star6 A, B, C, D(Figure2). Star6 receptor from deferent locations(Figure3) and Fig4 for star6 spike complex proteins which its bind in the RDB in extracellular and of the membrane part.

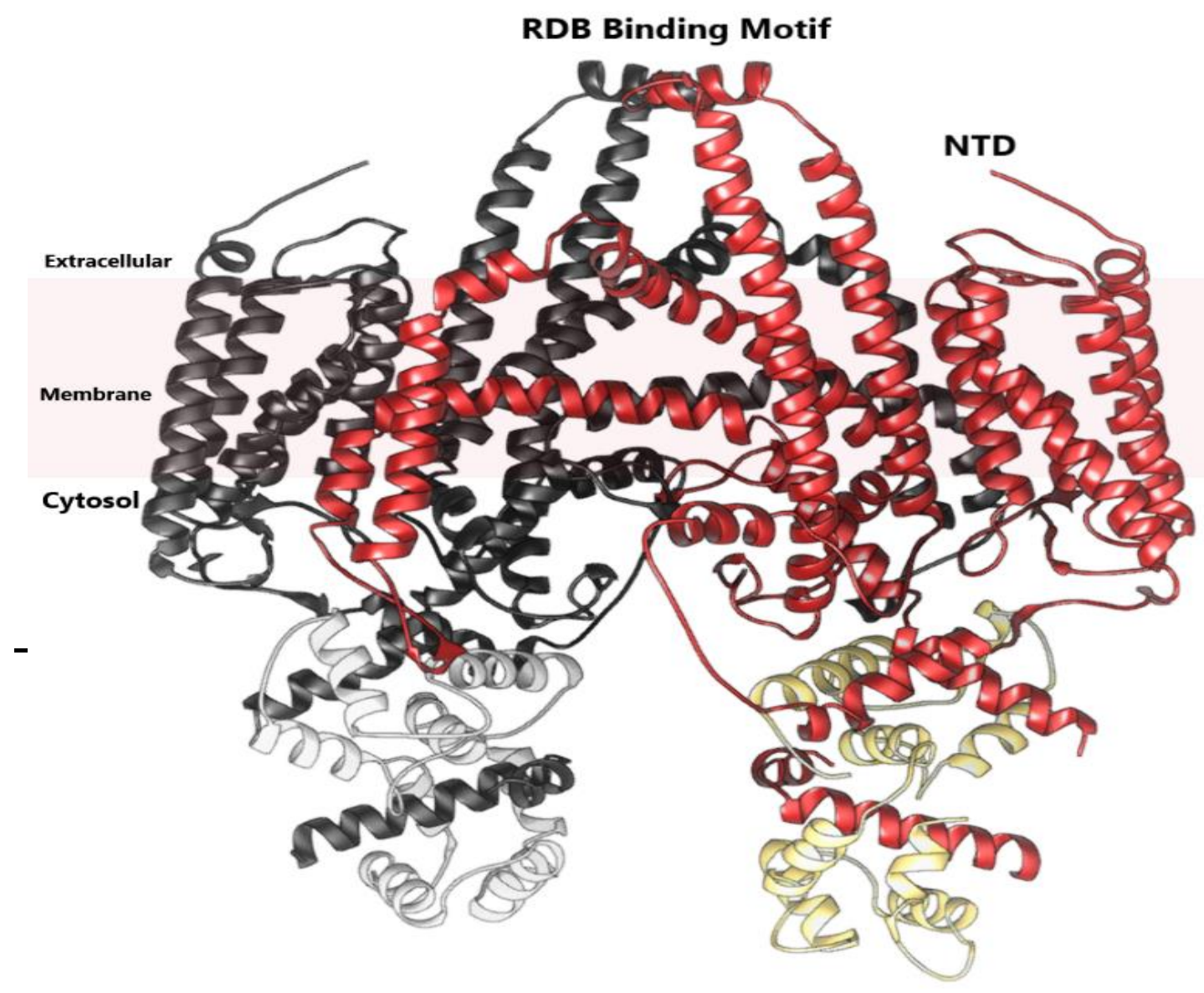


Fig2 : for star6 receptor with the extracellular, membrane and the third part in cytosol where star6 A, B, C , D
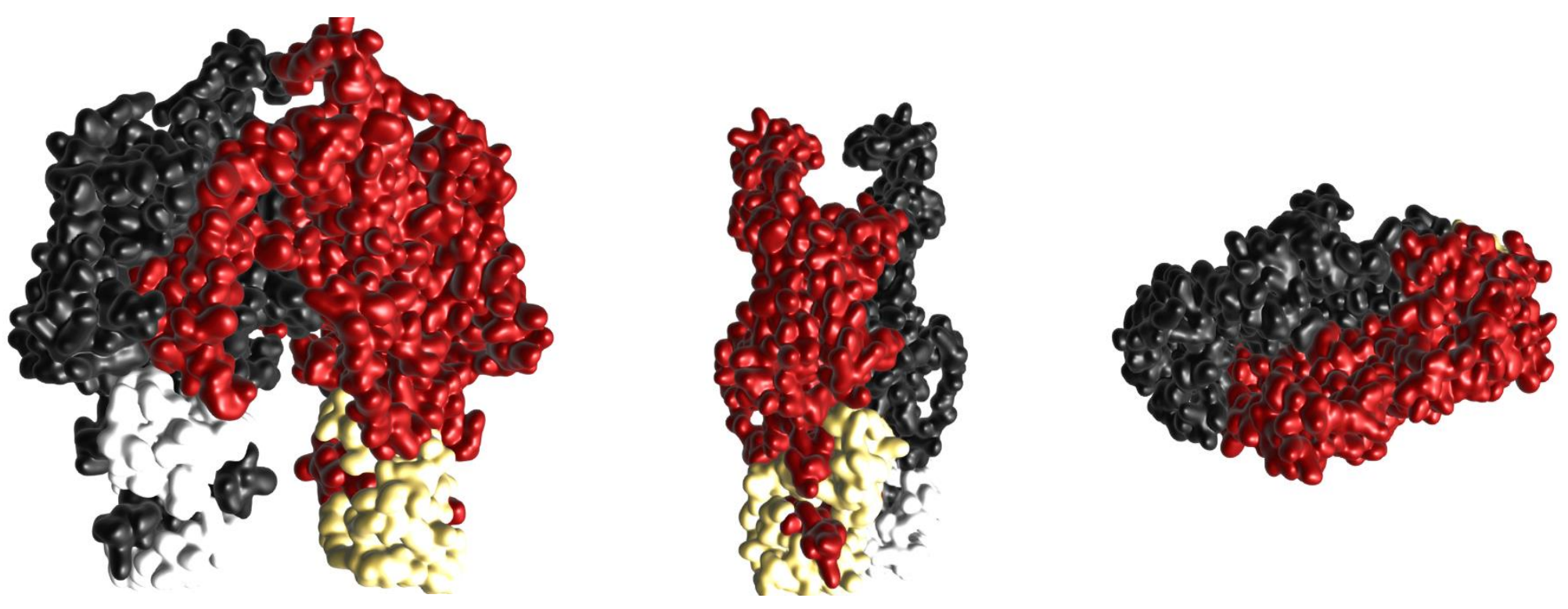

Fig3 for star6 receptor from deferent sites 

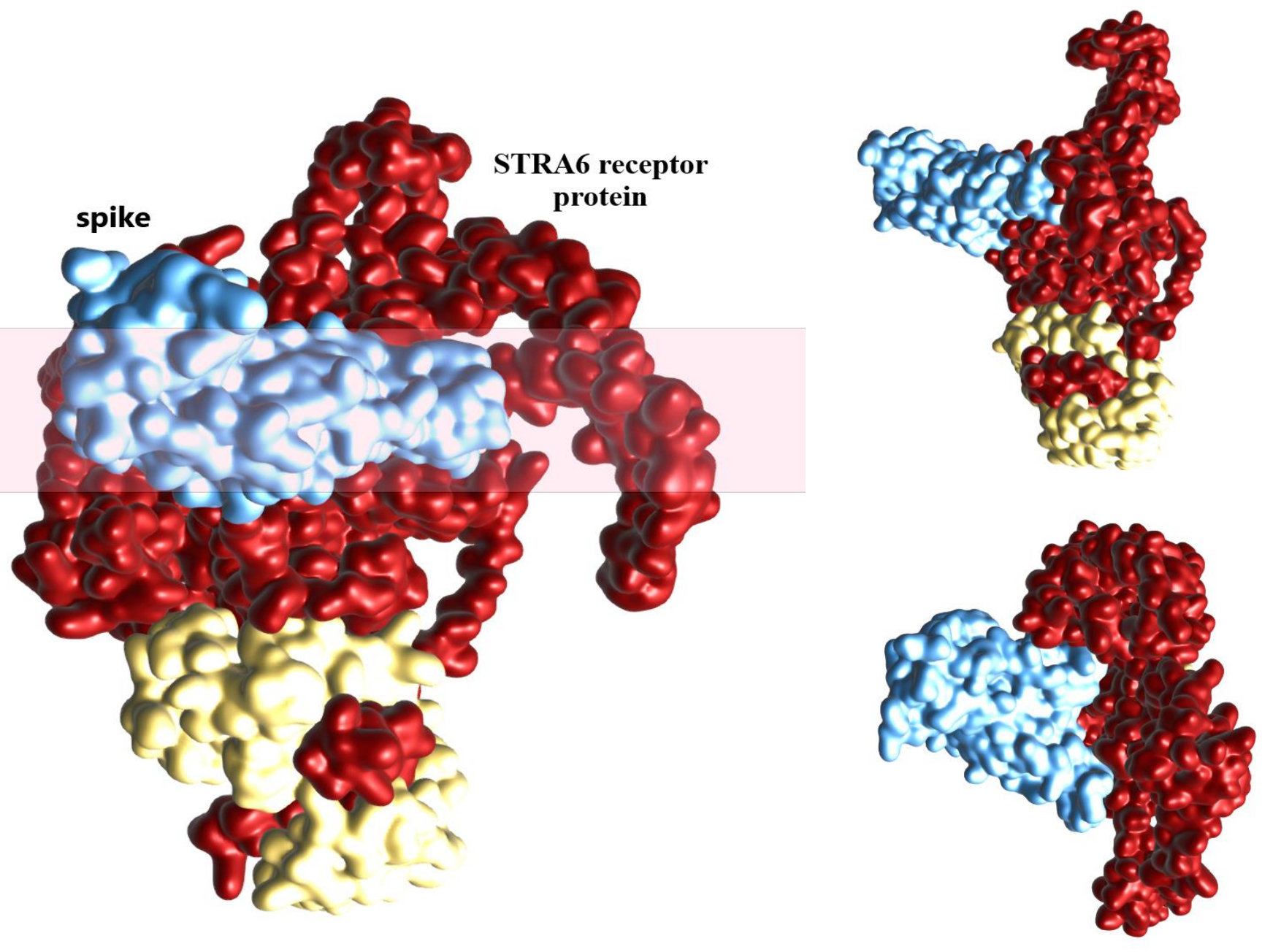

Fig4 for star6 spike complex proteins which its bind in the RDB in extracellular and of the membrane part

Results and discussion 
In this study, the Spike and STRA6 receptor protein was investigated for declare the mechanism of the interacting of the viral protein with the deferent symptoms of the patients and see the properties of the reaction for the first time, which could be used as alternative for therapeutic purposes. Here, the proteins of the Spike and STRA6 receptor were prepared and docked using HDOCK sever where the reaction are made between the spike protien and the STRA6 receptor for detection and declare the mode of action of the mechanism

\begin{tabular}{|c|c|c|c|c|c|c|c|c|c|}
\hline \multicolumn{9}{|c|}{ Complex Template Information between (STRA6 - SPIKE) } & \\
\hline Molecule & PDB ID & $\begin{array}{l}\text { Chain } \\
\text { ID }\end{array}$ & Align_length & Coverage & $\begin{array}{l}\text { Seq_ID } \\
(\%)\end{array}$ & Docking Score & $\begin{array}{l}\text { Ligand } \\
\text { rmsd }(\AA)\end{array}$ & LGscore: & MaxSub: \\
\hline $\begin{array}{l}\text { Receptor } \\
\text { (STRA6) }\end{array}$ & $\underline{5 S Y 1}$ & A & 582 & 0.793 & 96.2 & \multirow{2}{*}{-359.45} & \multirow[t]{2}{*}{229.41} & 2.416 & 0.147 \\
\hline $\begin{array}{l}\text { Ligand } \\
\text { (SPIKE) }\end{array}$ & $\underline{6 L Z G}$ & B & 194 & 1.000 & 100.0 & & & 5.056 & 0.217 \\
\hline \multicolumn{9}{|c|}{ Complex Template Information between (STRA6 - SPIKE) } & \\
\hline Molecule & PDB ID & $\begin{array}{l}\text { Chain } \\
\text { ID }\end{array}$ & Align_length & Coverage & $\begin{array}{l}\text { Seq_ID } \\
(\%)\end{array}$ & Docking Score & $\begin{array}{l}\text { Ligand } \\
\text { rmsd }(\AA)\end{array}$ & LGscore: & MaxSub: \\
\hline $\begin{array}{l}\text { Receptor } \\
\text { (SPIKE) }\end{array}$ & $\underline{7 D M U}$ & B & 196 & 1.000 & 100.0 & \multirow[t]{2}{*}{-354.68} & \multirow[t]{2}{*}{1.00} & 4.504 & 0.201 \\
\hline $\begin{array}{l}\text { Ligand } \\
\text { (ACE 2) }\end{array}$ & $\underline{7 D M U}$ & A & 597 & 1.000 & 100.0 & & & 6.618 & 0.396 \\
\hline
\end{tabular}

Table 1 Complex Template Information between and Docking scores ( spike protein, human STRA6 receptor protein ) and ( spike protein, ACE 2 ) where the PDB ID , chain ID of the protein, Aline length, coverage and seq ID , Docking scores , RMSD , LGscore and MaxSub which resulted from HDock

\section{Protien protien Docking studies(STRA6 and ligand spike protein)}

The interactive residues of target protein STRA6 and ligand spike protein that will help the researchers to design and develop the drugs that are more efficient and specific for their target protein. The docking of STRA6 target protein with spike viral protein which revealed the involvement of the spike protein into the extracellular and membrane part of the STRA6 receptor and amino acids residues of STRA6 along with spike protein which make interactions and play an important role in formation of complexes. STRA6Spike protein complex with PDB ID $(\underline{5 S Y 1}, \underline{6 \mathrm{LZG}})$ representatively ,the chain A ,B with Align - length $(582,194)$ then the quarry coverage of proteins 0.793 and 1.000 with sequence identity $96.2 \%$ and 100,0\% representatively. The surface view of complex reveals that the binding 
pocket of STRA6- Spike protein and Spike ACE 2 complexes with RMSD $(189.44 \AA, 1.00 \AA)$ representatively and docking score $(-341.21,-354.68)$ $\mathrm{kcal} / \mathrm{mol}$ the quality of the receptor and the ligand are LGscore and MaxSub $(2.416,0.147$ ) where the structure are correct representatively for the STRA6 receptor protein, and LGscore and MaxSub ,5.056,0.217) where the structure are very good and correct representatively for the Spike ligand protein see (table 1) .

\section{Protein-Protein Interaction Network(STRA6 receptor and five interacting partners from both shells of interactions)}

The protein-protein interaction associative network for the STRA6 receptor through STRING server. The active interaction sources were set based on the seven parameters including experiments, co-expression, gene fusion, cooccurrence, databases, text mining, and neighborhood. with a maximum of five interacting partners from both shells of interactions. The color nodes describe query proteins and the first shell of interactions, whereas white nodes are the second shell of interactors. The large node size represents characterized proteins and smaller nodes for characterized proteins which the number of nodes: 7 , number of edges 10 , average node degree 2.86 , avg. local clustering coefficient 0.895 , expected number of edges 6 and also PPI enrichment p-value 0.0973 . The functional interactive network formed by STRA6 receptor protein was analyzed at the medium confidence level (0.40) has been shown in Figure(1).

The protein was shown to have an interaction with RBP4 Retinol-binding protein 4; Retinol-binding protein that mediates retinol transport in blood plasma, TTR ransthyretin; Thyroid hormonebinding protein. Probably transports thyroxine from the bloodstream to the brain , RBP1 Retinol-binding protein 1; Cytoplasmic retinol-binding protein. Accepts retinol from the transport protein STRA6, CALM3 Calmodulin 3 (phosphorylase kinase, delta); Calmodulin mediates the control of a large number of enzymes, ion channels, , CALM2 Calmodulin 2 (phosphorylase kinase, delta); EF-hand domain containing and CALM1 Calmodulin-1; Calmodulin mediates the control of a large number of enzymes, ion channels, aquaporins and other proteins with score ( 0.983 , $0.881,0.733,0.551,0.421$ and 0.421 ) representatively . also its interact with deferent processes biological processes, molecular function, cellular 
compounds, reactome pathways, disease gen associations Tissue expression and also the subcellular localization

\section{Analysis of binding energy in complex}

The interactive residues of target protein STRA 6 and ligand spike protein that will help the researchers to design and develop the drugs that are more efficient and specific for their target protein. The docking of STRA6 target protein with spike viral protein which revealed the involvement of the spike protein into the extracellular and membrane part of the STRA6 receptor and amino acids residues of STRA6 along with spike protein which make interactions and play an important role in formation of complexes the corresponding distances about the residue contacts between proteins STRA6- Spike protein complex are in table 2 where the STRA6- Spike protein complexes binding site are bind to the RDB of the CHOLESTEROL to STRA6 receptor which is bind with interface residue( ARG 511A, VAL 512A THR 515A ALA 516A ASN 519A with interface residue degree $(2.965,3.595,3.286,4.592$, and 4.235) representatively also the ability of the spike to bind to RDB of the STRA 6 protein(fig5) in the ILE 131C , MET 145C , HIS 86A with interface residue( $4.961,4.953$ and 3.271) representatively

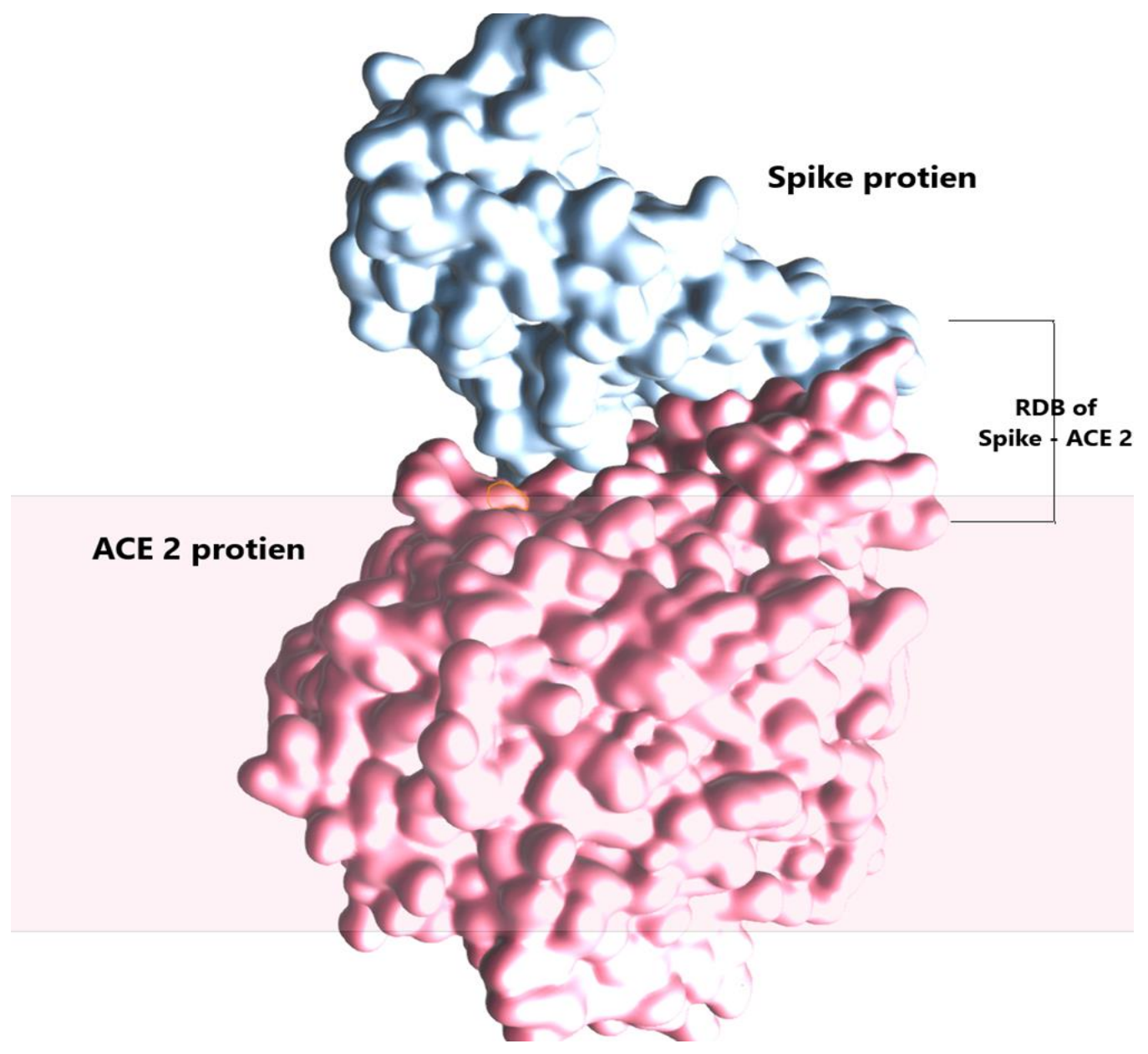




\section{Figure 5 The spike to bind to RDB of the STRA 6 protein}

Table 2 contain the full details about the binding pocket of the RDB of the STRA 6 protein Receptor interface residue with the spike viral protein Ligand interface residue with their amino acid number and the RMSD of the interface residues

\begin{tabular}{|cc|c|cc|c|c|c|}
\hline \multicolumn{2}{|c|}{$\begin{array}{r}\text { Receptor interface residue(s) } \\
\text { STRA 6 protein }\end{array}$} & \multicolumn{2}{c|}{$\begin{array}{c}\text { Ligand interface residue(s): } \\
\text { spike viral protein }\end{array}$} & \multicolumn{2}{c|}{$\begin{array}{c}\text { Receptor-ligand interface residue pair(s) } \\
\text { STRA 6 - spike }\end{array}$} \\
\hline PHE & 98A & 4.825 & THR & 345 & 3.385 & $98 \mathrm{~A}-446$ & 4.825 \\
\hline LEU & $101 \mathrm{~A}$ & 2.600 & ARG & 403 & 3.484 & $101 \mathrm{~A}-445$ & 2.600 \\
\hline GLU & $121 \mathrm{~A}$ & 3.385 & ASP & 405 & 2.898 & $101 \mathrm{~A}-446$ & 3.688 \\
\hline PHE & $122 \mathrm{~A}$ & 3.261 & ARG & 408 & 3.542 & $121 \mathrm{~A}-345$ & 3.385 \\
\hline ILE & $125 \mathrm{~A}$ & 1.963 & LYS & 417 & 2.815 & $122 \mathrm{~A}-440$ & 3.806 \\
\hline LEU & $128 \mathrm{~A}$ & 3.081 & ASN & 440 & 1.963 & $122 \mathrm{~A}-441$ & 3.261 \\
\hline LEU & $129 \mathrm{~A}$ & 4.782 & LEU & 441 & 3.261 & $125 \mathrm{~A}-440$ & 1.963 \\
\hline ARG & $393 \mathrm{~A}$ & 2.898 & SER & 443 & 3.229 & $125 \mathrm{~A}-441$ & 3.276 \\
\hline PRO & $394 \mathrm{~A}$ & 2.945 & LYS & 444 & 3.081 & $128 \mathrm{~A}-443$ & 3.229 \\
\hline ALA & $395 \mathrm{~A}$ & 4.958 & VAL & 445 & 2.600 & $128 \mathrm{~A}-444$ & 3.081 \\
\hline VAL & $397 \mathrm{~A}$ & 2.104 & GLY & 446 & 2.397 & $128 \mathrm{~A}-445$ & 3.690 \\
\hline CYS & $398 \mathrm{~A}$ & 2.971 & GLY & 447 & 4.521 & $128 \mathrm{~A}-499$ & 4.986 \\
\hline MET & $400 \mathrm{~A}$ & 3.268 & TYR & 449 & 2.841 & $129 \mathrm{~A}-499$ & 4.782 \\
\hline GLY & $401 \mathrm{~A}$ & 3.923 & TYR & 453 & 4.496 & $393 \mathrm{~A}-405$ & 2.898 \\
\hline SER & $404 \mathrm{~A}$ & 2.828 & LEU & 455 & 3.064 & $393 \mathrm{~A}-408$ & 3.542 \\
\hline TYR & $405 \mathrm{~A}$ & 2.076 & PHE & 456 & 3.345 & $393 \mathrm{~A}-504$ & 4.869 \\
\hline ALA & $407 \mathrm{~A}$ & 4.932 & THR & 478 & 2.965 & $394 \mathrm{~A}-403$ & 4.451 \\
\hline ALA & $408 \mathrm{~A}$ & 2.397 & CYS & 480 & 4.585 & $394 \mathrm{~A}-405$ & 4.088 \\
\hline PHE & $409 \mathrm{~A}$ & 3.185 & ASN & 481 & 4.31 & $394 \mathrm{~A}-505$ & 2.945 \\
\hline LEU & $412 \mathrm{~A}$ & 4.520 & VAL & 483 & 3.595 & $395 \mathrm{~A}-505$ & 4.958 \\
\hline ARG & $511 \mathrm{~A}$ & 2.965 & GLU & 484 & 2.855 & $397 \mathrm{~A}-501$ & 4.170 \\
\hline VAL & $512 \mathrm{~A}$ & 3.595 & GLY & 485 & 3.286 & $397 \mathrm{~A}-502$ & 3.186 \\
\hline THR & $515 \mathrm{~A}$ & 3.286 & PHE & 486 & 3.152 & $397 \mathrm{~A}-503$ & 4.476 \\
\hline ALA & $516 \mathrm{~A}$ & 4.592 & ASN & 487 & 3.408 & $397 \mathrm{~A}-504$ & 4.045 \\
\hline
\end{tabular}




\begin{tabular}{|c|c|c|c|c|c|}
\hline ASN 519A & 4.235 & TYR 489 & 1.928 & $397 A-505$ & 2.104 \\
\hline LEU $530 \mathrm{~A}$ & 4.709 & GLN 493 & 3.539 & $398 A-505$ & 2.971 \\
\hline LEU $531 \mathrm{~A}$ & 1.928 & SER 494 & 4.607 & $400 A-500$ & 3.268 \\
\hline ASN $532 \mathrm{~A}$ & 2.782 & GLY 496 & 3.025 & $400 A-501$ & 3.411 \\
\hline VAL $535 \mathrm{~A}$ & 3.116 & GLN 498 & 2.076 & $400 A-502$ & 3.860 \\
\hline PHE 538A & 2.815 & $\begin{array}{ll}\text { PRO } & 499\end{array}$ & 4.782 & $401 \mathrm{~A}-498$ & 4.759 \\
\hline ASP $539 A$ & 4.610 & THR 500 & 3.268 & $401 \mathrm{~A}-500$ & 3.923 \\
\hline $\begin{array}{ll}\text { PRO } 540 A \\
\end{array}$ & 3.539 & ASN 501 & 3.038 & $401 \mathrm{~A}-501$ & 4.401 \\
\hline ARG $543 \mathrm{~A}$ & 2.466 & GLY 502 & 3.186 & $404 A-446$ & 3.954 \\
\hline CYS 544A & 4.859 & VAL 503 & 4.476 & $404 \mathrm{~A}-498$ & 2.828 \\
\hline CLR 701A & 2.855 & GLY 504 & 4.045 & $404 A-500$ & 4.395 \\
\hline & & TYR 505 & 2.104 & $404 \mathrm{~A}-501$ & 4.772 \\
\hline & & & & $405 \mathrm{~A}-449$ & 4.362 \\
\hline & & & & $405 \mathrm{~A}-496$ & 3.025 \\
\hline & & & & $405 \mathrm{~A}-498$ & 2.076 \\
\hline & & & & $405 \mathrm{~A}-501$ & 3.038 \\
\hline & & & & $405 \mathrm{~A}-505$ & 4.742 \\
\hline & & & & $407 A-446$ & 4.932 \\
\hline & & & & $408 \mathrm{~A}-446$ & 2.397 \\
\hline & & & & $408 \mathrm{~A}-447$ & 4.521 \\
\hline & & & & $408 \mathrm{~A}-449$ & 2.841 \\
\hline & & & & $408 \mathrm{~A}-498$ & 4.101 \\
\hline & & & & $409 A-449$ & 3.185 \\
\hline & & & & $412 \mathrm{~A}-449$ & 4.520 \\
\hline & & & & $511 A-478$ & 2.965 \\
\hline & & & & $511 A-486$ & 3.152 \\
\hline & & & & $512 A-480$ & 4.585 \\
\hline & & & & $512 A-481$ & 4.318 \\
\hline & & & & $512 A-483$ & 3.595 \\
\hline & & & & $512 A-484$ & 4.812 \\
\hline & & & & $515 \mathrm{~A}-484$ & 3.589 \\
\hline & & & & $515 A-485$ & 3.286 \\
\hline & & & & $515 A-486$ & 3.288 \\
\hline & & & & $516 A-484$ & 4.592 \\
\hline & & & & $519 A-484$ & 4.235 \\
\hline & & & & $530 A-489$ & 4.709 \\
\hline & & & & $531 A-455$ & 4.937 \\
\hline
\end{tabular}




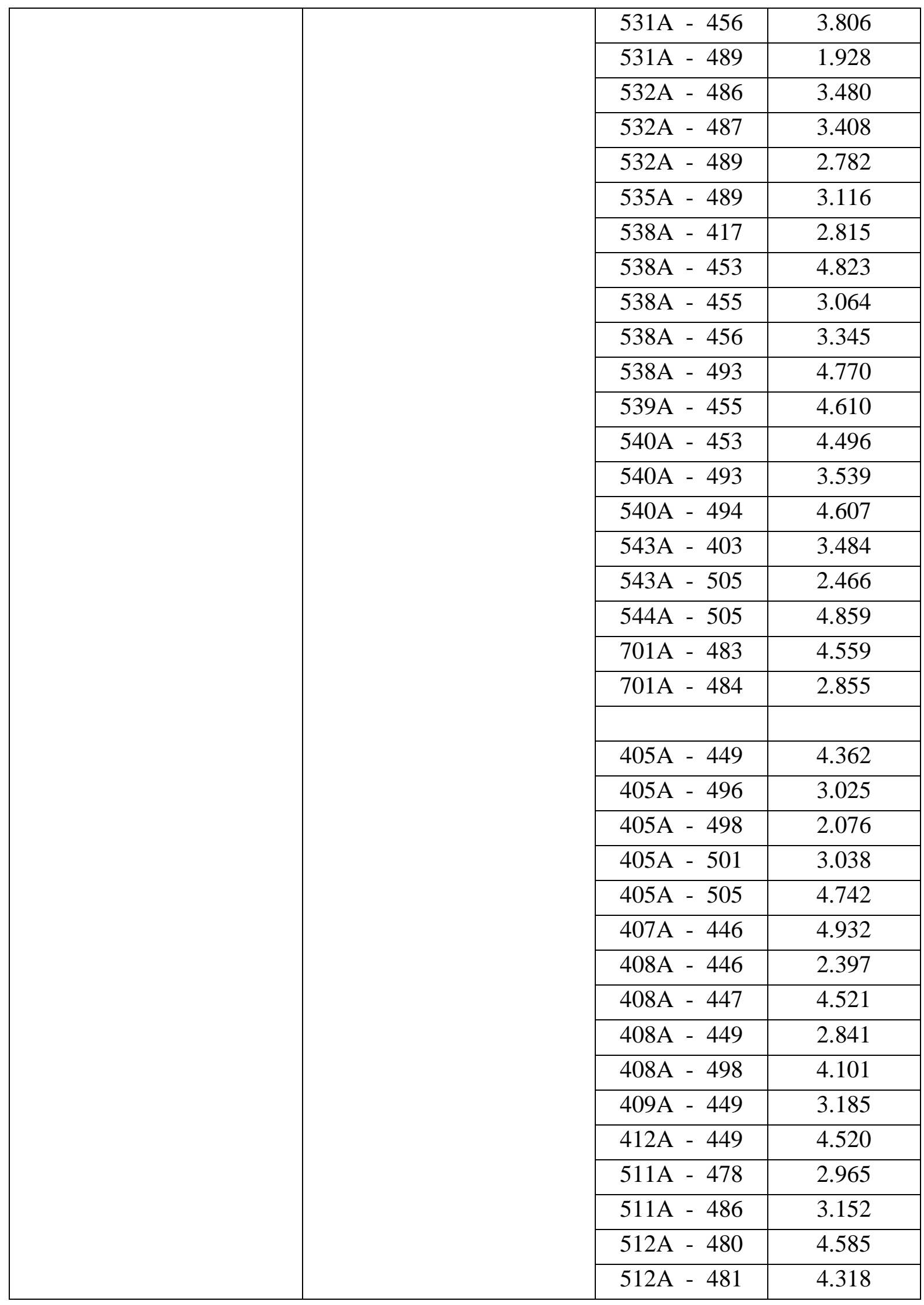




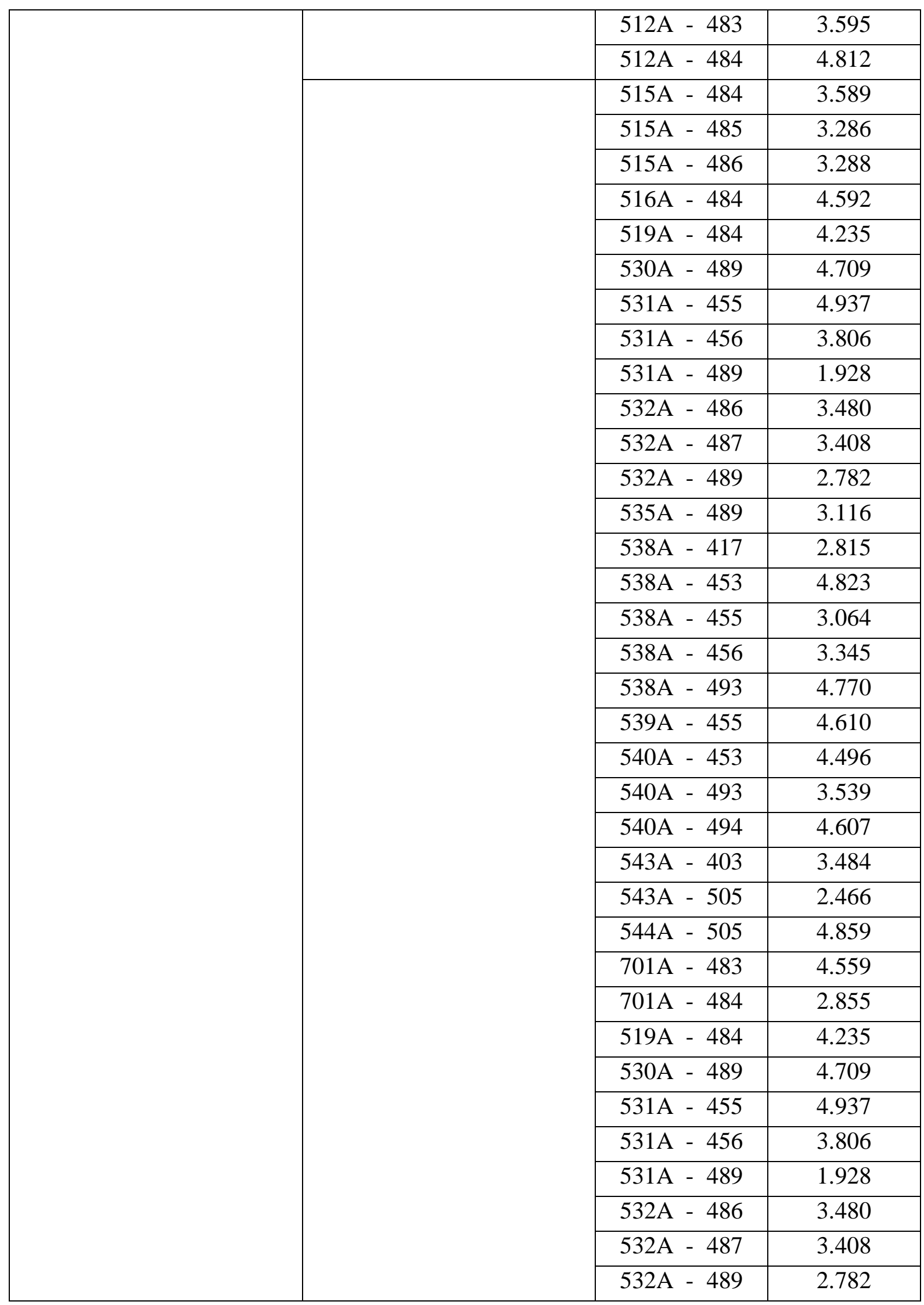




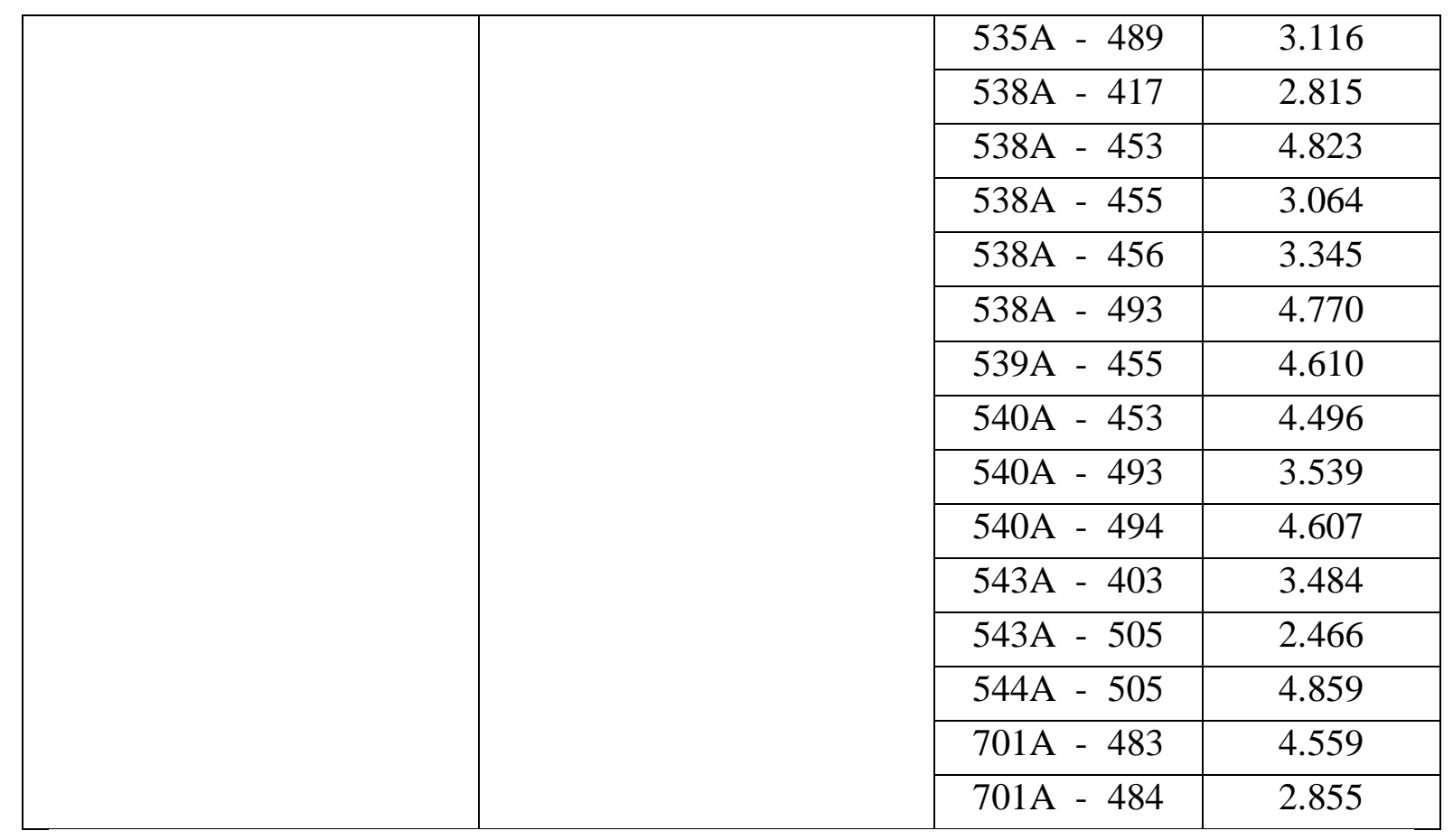

\section{Conflict of Interest Statement}

The author declares that the research was conducted in the absence of any commercial or financial relationships that could be construed as a potential conflict of interest.

\section{Reverences}

1-Chen, Y., Clarke, O. B., Kim, J., Stowe, S., Kim, Y. K., Assur, Z., Cavalier, M., Godoy-Ruiz, R., von Alpen, D. C., Manzini, C., Blaner, W. S., Frank, J., Quadro, L., Weber, D. J., Shapiro, L., Hendrickson, W. A., \&Mancia, F. (2016). Structure of the STRA6 receptor for retinol uptake. Science (New York, N.Y.), 353(6302), aad8266. https://doi.org/10.1126/science.aad8266.

2- Kelly, Mary, and Johannes von Lintig. "STRA6: role in cellular retinol uptake and efflux." Hepatobiliary surgery and nutrition vol. 4,4 (2015): 229-42. doi:10.3978/j.issn.23043881.2015.01.12

3- Barrett, Crisha et al. "Human Peripheral Blood Mononuclear Cells Express High Levels of the Vitamin a Transport Protein, Stimulated by Retinoic Acid 6 (P19-004-19)." Current Developments in Nutrition vol. 3,Suppl 1 nzz049.P19-004-19. 13 Jun. 2019, doi:10.1093/cdn/nzz049.P19-004-19 
4-Developmental expression pattern of Stra6, a retinoic acid-responsive gene encoding a new type of membrane protein. Bouillet P, Sapin V, Chazaud C, Messaddeq N, Décimo D, Dollé P, Chambon P Mech Dev. 1997 May; 63(2):173-86.

5-Receptor-mediated cellular uptake mechanism that couples to intracellular storage. Kawaguchi R, Yu J, Ter-Stepanian M, Zhong M, Cheng G, Yuan Q, Jin M, Travis GH, Ong D, Sun HACS Chem Biol. 2011 Oct 21; 6(10):1041-51.

6- RBP4 disrupts vitamin A uptake homeostasis in a STRA6-deficient animal model for MatthewWood syndrome. Isken A, Golczak M, Oberhauser V, Hunzelmann S, Driever W, Imanishi Y, Palczewski K, von Lintig J Cell Metab. 2008 Mar; 7(3):258-68.

7-Case-control analysis of SNPs in GLUT4, RBP4 and STRA6: association of SNPs in STRA6 with type 2 diabetes in a South Indian population. Nair AK, Sugunan D, Kumar H, Anilkumar G PLoS One. 2010 Jul 6; 5(7):e11444.

8-Pasutto, F., Sticht, H., Hammersen, G., Gillessen-Kaesbach, G., Fitzpatrick, D. R., Nürnberg, G., Brasch, F., Schirmer-Zimmermann, H., Tolmie, J. L., Chitayat, D., Houge, G., FernándezMartínez, L., Keating, S., Mortier, G., Hennekam, R. C. M., von der Wense, A., Slavotinek, A., Meinecke, P., Bitoun, P., ... Rauch, A. (2007). Mutations in STRA6 cause a broad spectrum of malformations including anophthalmia, congenital heart defects, diaphragmatic hernia, alveolar capillary dysplasia, lung hypoplasia, and mental retardation. American Journal of Human Genetics, 80(3), 550-60. https://doi.org/10.1086/512203

9-A puzzle over several decades: eye anomalies with FRAS1 and STRA6 mutations in the same family.

Ng WY, Pasutto F, Bardakjian TM, Wilson MJ, Watson G, Schneider A, Mackey DA, Grigg JR, Zenker M, Jamieson RV

Clin Genet. 2013 Feb; 83(2):162-8.

10-Phenotypic spectrum of STRA6 mutations: from Matthew-Wood syndrome to non-lethal anophthalmia.

Chassaing N, Golzio C, Odent S, Lequeux L, Vigouroux A, Martinovic-Bouriel J, Tiziano FD, Masini L, Piro F, Maragliano G, Delezoide AL, Attié-Bitach T, Manouvrier-Hanu S, Etchevers HC, Calvas $P$

Hum Mutat. 2009 May; 30(5):E673-81

11-Retinoid content, visual responses, and ocular morphology are compromised in the retinas of mice lacking the retinol-binding protein receptor, STRA6.

Ruiz A, Mark M, Jacobs H, Klopfenstein M, Hu J, Lloyd M, Habib S, Tosha C, Radu RA, Ghyselinck NB, Nusinowitz S, Bok D

Invest Ophthalmol Vis Sci. 2012 May 17; 53(6):3027-39.

12-Signaling by vitamin $\mathrm{A}$ and retinol-binding protein regulates gene expression to inhibit insulin responses.

Berry DC, Jin H, Majumdar A, Noy N

ProcNatIAcadSci U S A. 2011 Mar 15; 108(11):4340-5 
13. Palczewski K. Chemistry and biology of vision. J Biol Chem. 2012;287:1612-1619. doi: 10.1074/jbc.R111.301150.

14. Al Tanoury Z, Piskunov A, Rochette-Egly C. Vitamin A and retinoid signaling: Genomic and nongenomic effects. J Lipid Res. 2013;54:1761-1775. doi: 10.1194/jlr.R030833.

15. Goodman DS. Vitamin A and retinoids in health and disease. N Engl J Med. 1984;310:10231031. doi: 10.1056/NEJM198404193101605. [PubMed] [CrossRef] [Google Scholar]

16. Shirakami Y, Lee SA, Clugston RD, Blaner WS. Hepatic metabolism of retinoids and disease associations. BiochimBiophysActa. 2012;1821:124-136. doi: 10.1016/j.bbalip.2011.06.023. [PMC free article] [PubMed] [CrossRef] [Google Scholar]

17. di Masi A, et al. Retinoic acid receptors: From molecular mechanisms to cancer therapy. Mol Aspects Med. 2015;41:1-115. doi: 10.1016/j.mam.2014.12.003. [PubMed] [CrossRef] [Google Scholar]

18. West KP., Jr Extent of vitamin A deficiency among preschool children and women of reproductive age. J Nutr. 2002;132:2857S-2866S.

19-Kin Ting Kam, R., Deng, Y., Chen, Y. et al. Retinoic acid synthesis and functions in early embryonic development. Cell Biosci 2, 11 (2012). https://doi.org/10.1186/2045-3701-2$\underline{11}$

20-Pino-Lagos K, Benson MJ, Noelle RJ. Retinoic acid in the immune system. Ann N Y Acad Sci. 2008 Nov;1143:170-87. doi: 10.1196/annals.1443.017. PMID: 19076350; PMCID: PMC3826166.

21-Raverdeau M, Mills KH. Modulation of T cell and innate immune responses by retinoic Acid. J Immunol. 2014 Apr;192(7):2953-8. PubMed PMID: 24659788. eng. 
22-Ross AC, Stephensen CB. Vitamin A and retinoids in antiviral responses. FASEB J. 1996 Jul;10(9):979-85. PubMed PMID: 8801180. Eng

23-Kim CH. Control of Innate and Adaptive Lymphocytes by the RAR-Retinoic Acid Axis. Immune Netw. 2018 Jan 18;18(1):e1. doi: 10.4110/in.2018.18.e1. PMID: 29503736; PMCID: PMC5833116.

22-Karunanithi, Sheelarani et al. "RBP4-STRA6 Pathway Drives Cancer Stem Cell Maintenance and Mediates High-Fat Diet-Induced Colon Carcinogenesis." Stem cell reports vol. 9,2 (2017): 438-450. doi:10.1016/j.stemcr.2017.06.002

23-Barclay JL, Anderson ST, Waters MJ, Curlewis JD. SOCS3 as a tumor suppressor in breast cancer cells, and its regulation by PRL. Int J Cancer. 2009 Apr 15;124(8):1756-66. doi: 10.1002/ijc.24172. PMID: 19115200.

24-Berry, Daniel $\mathrm{C}$ et al. "Signaling by vitamin A and retinol-binding protein regulates gene expression to inhibit insulin responses." Proceedings of the National Academy of Sciences of the United States of America vol. 108,11 (2011): 4340-5. doi:10.1073/pnas.1011115108

25-Babon, J. J., Varghese, L. N., \& Nicola, N. A. (2014). Inhibition of IL-6 family cytokines by SOCS3. Seminars in immunology, 26(1), 13-19. https://doi.org/10.1016/j.smim.2013.12.004

26-Croker BA, Krebs DL, Zhang JG, Wormald S, Willson TA, Stanley EG, Robb L, Greenhalgh CJ, Förster I, Clausen BE, Nicola NA, Metcalf D, Hilton DJ, Roberts AW, Alexander WS. SOCS3 negatively regulates IL-6 signaling in vivo. Nat Immunol. 2003 Jun;4(6):540-5. doi: 10.1038/ni931. Epub 2003 May 18. PMID: 12754505.

27-Huang KJ, Su IJ, Theron M, Wu YC, Lai SK, Liu CC, Lei HY. An interferongamma-related cytokine storm in SARS patients. J Med Virol. 2005 Feb;75(2):18594. doi: 10.1002/jmv.20255. PMID: 15602737; PMCID: PMC7166886. 28-Johnson HM, Lewin AS, Ahmed CM. SOCS, Intrinsic Virulence Factors, and Treatment of COVID-19. Front Immunol. 2020 Oct 23;11:582102. doi: 10.3389/fimmu.2020.582102. PMID: 33193390; PMCID: PMC7644869. 
29-Merad, M., Martin, J.C. Pathological inflammation in patients with COVID-19: a key role for monocytes and macrophages. Nat Rev Immunol 20,355-362 (2020). https://doi.org/10.1038/s41577-020-0331-4

30-Fedders R, Muenzner M, Schupp M. Retinol binding protein 4 and its membrane receptors: a metabolic perspective. HormMolBiolClin Invest. 2015;22(1):27-37

31-Tepasse, P.-R.; Vollenberg, R.; Fobker, M.; Kabar, I.; Schmidt, H.; Meier, J.A.; Nowacki, T.; HüsingKabar, A. Vitamin A Plasma Levels in COVID-19 Patients: A Prospective Multicenter Study and Hypothesis. Nutrients 2021, 13, 2173. https://doi.org/10.3390/nu13072173

32-Norseen J, Hosooka T, Hammarstedt A, Yore MM, Kant S, Aryal P, Kiernan UA, Phillips DA, Maruyama H, Kraus BJ, Usheva A, Davis RJ, Smith U, Kahn BB. Retinolbinding protein 4 inhibits insulin signaling in adipocytes by inducing proinflammatory cytokines in macrophages through a c-Jun $\mathrm{N}$-terminal kinaseand toll-like receptor 4-dependent and retinol-independent mechanism. Mol Cell Biol. 2012 May;32(10):2010-9. doi: 10.1128/MCB.06193-11. Epub 2012 Mar 19. PMID: 22431523; PMCID: PMC3347417.

33-Ruan, Q. , Yang, K. , Wang, W. , Jiang, L. , \& Song, J. (2020). Clinical predictors of mortality due to COVID-19 based on an analysis of data of 150 patients from Wuhan, China. Intensive Care Medicine, 40(5), 846-848. 10.1007/s00134-020-05991-x

34-Devaprasad A, Pandit A. Enrichment of SARS-CoV-2 entry factors and interacting intracellular genes in peripheral immune cells. bioRxiv; 2021. DOI: 10.1101/2021.03.29.437515 